\title{
Universal Current-Controlled Current-Mode Biquad Filter Employing MO-CCCCTAs and Grounded Capacitors
}

\author{
Sajai Vir Singh ${ }^{1}$, Sudhanshu Maheshwari ${ }^{2}$, Durg Singh Chauhan ${ }^{3}$ \\ ${ }^{1}$ Department of Electronics and Communications, Jaypee University of Information Technology, \\ Waknaghat, India \\ ${ }^{2}$ Department of Electronics Engineering, Z. H. College of Engineering and Technology, Aligarh Muslim University, \\ Aligarh, India \\ ${ }^{3}$ Department of Electrical Engineering, Institute of Technology, Banaras Hindu University, \\ Varanasi, India \\ E-mail: \{sajaivir,sudhanshu_maheshwari\}@rediffmail.com,pdschauhan@gmail.com \\ Received May 22, 2010; revised July 19, 2010; accepted July 23, 2010
}

\begin{abstract}
This paper presents a universal current-controlled current-mode biquad filter employing current controlled current conveyor trans-conductance amplifiers (CCCCTAs). The proposed filter employs only three MOCCCCTAs and two grounded capacitors. The proposed filter can simultaneously realize low pass (LP), band pass (BP), high pass (HP), band reject (BR) and all pass (AP) responses in current form by choosing appropriate current output branches. In addition, the pole frequency and quality factor of the proposed filter circuit can be tuned independently and electronically over the wide range by adjusting the external bias currents. The circuit possesses low active and passive sensitivity performance. The validity of proposed filter is verified through PSPICE simulations.
\end{abstract}

Keywords: Biquad, Current-Mode, Universal Filter

\section{Introduction}

It is well accepted that universal biquad filter is a very important functional block which is widely used in various parts such as communication, measurement, instrumentation and control systems [1]. Because of the well known advantages such as reduced distortions, low input impedance, high output impedance, less sensitive to switching noise, better ESD immunity, high slew rate and larger bandwidth, the design and implementation of current-mode active filters using current-mode active elements [2] have become quite popular for wide variety of applications due to their inherent advantages over the voltage-mode counter parts. Recently, a new current-mode active element, namely the current controlled current conveyor trans-conductance amplifiers (CCCCTAs) has been introduced [3]. Its trans-conductance and parasitic resistance can be adjusted electronically, hence it does not need a resistor in practical applications. This device can be operated in both current and voltage-modes, providing flexibility. In addition, it can offer several advantages such as high slew rate, high speed, wider bandwidth and simpler implementation. All these advantages together, its current-mode operation makes the CCCCTA, a promising choice for realizing active filters [4]. During the last one decade and recent past a number of universal current-mode active filters have been reported in the literature [5-23], using different current-mode active elements. Unfortunately these reported current-mode filters [5-23] suffer from one or more of the following drawbacks:

1) Lack of electronic tunability $[5,7,9,11,20]$.

2) Can not provide completely standard filter functions simultaneously [8,13,15,18,21-23].

3) Excessive use of active and/or passive elements [5,6,9, 11,12,14,16-19].

4) Can not provide explicit current outputs $[8,13,15]$.

5) Pole frequency and quality factor can't be controlled orthogonally $[8,10,22]$.

In this paper a new universal current-controlled current-mode biquad filter using three MO-CCCCTAs and two grounded capacitors is proposed. The proposed filter can simultaneously realize LP, BP, HP, BR and AP responses in current form. In addition, the pole frequency and quality factor of the proposed filter circuit can be tuned independently and electronically over the wide 
range by adjusting the external bias currents. Both the active and passive sensitivities are less and no longer than one. The validity of proposed filter is verified through PSPICE, the industry standard tool.

\section{Proposed Circuit}

The CCCCTA properties can be described by the following equations

$$
V_{X i}=V_{Y i}+I_{X i} R_{X i}, I_{Z i}=I_{X i}, \quad I_{ \pm O}= \pm g_{m i} V_{Z i}
$$

where $R_{X i}$ and $g_{m i}$ are the parasitic resistance at $X$ terminal and transconductance of the $i^{\text {th }}$ CCCCTA, respectively. $R_{X i}$ and $g_{m i}$ depend upon the biasing currents $I_{B i}$ and $I_{S i}$ of the CCCCTA, respectively. The schematic symbol of MO-CCCCTA is illustrated in Figure 1. For BJT model of MO-CCCCTA [3] shown in Figure 2, $R_{X i}$ and $g_{m i}$ can be expressed as

$$
R_{X i}=\frac{V_{T}}{2 I_{B i}} \text { and } g_{m i}=\frac{I_{S i}}{2 V_{T}}
$$

The proposed current-mode universal filter is shown in Figure 3. It is based on three MO-CCCCTAs and two grounded capacitors. Routine analysis of proposed filter yields the circuit transfer functions $T_{L P}(s), T_{B P}(s), T_{H P}(s)$, $T_{B R}(s)$ and $T_{A P}(s)$ for the current outputs $I_{L P}(s), I_{B P}(s)$, $I_{H P}(s), I_{B R}(s)$ and $I_{A P}(s)$ and can be formulated as

$$
\begin{aligned}
& T_{L P}(s)=\frac{I_{L P}(s)}{I_{i n}(s)}= \\
& -g_{m 1} R_{X 1} \frac{g_{m 2}}{s^{2} C_{1} C_{2} R_{X 2}+s g_{m 1} R_{X 1} C_{2}+g_{m 2}} \\
& T_{H P}(s)=\frac{I_{H P}(s)}{I_{i n}(s)}= \\
& g_{m 1} R_{X 1} \frac{s^{2} C_{1} C_{2} R_{X 2}}{s^{2} C_{1} C_{2} R_{X 2}+s g_{m 1} R_{X 1} C_{2}+g_{m 2}} \\
& T_{B P}(s)=\frac{I_{B P}(s)}{I_{i n}(s)}= \\
& -g_{m 1} R_{X 1} \frac{s C_{2} g_{m 3} R_{X 3}}{2} \\
& T_{B R}(s)=\frac{I_{B R}(s)}{I_{i n}(s)}= \\
& g_{m 1} R_{X 1} \frac{s^{2} C_{1} C_{2} R_{X 2}+g_{m 2}+s g_{m 1} R_{X 1} C_{2}+g_{m 2}}{s^{2} C_{1} C_{2} R_{X 2}+s g_{m 1} R_{X 1} C_{2}+g_{m 2}} \\
& T_{A P}(s)=\frac{I_{A P}(s)}{I_{i n}(s)}= \\
& s^{2} C_{1} C_{2} R_{X 2}+s g_{m 1} R_{X 1} C_{2}+g_{m 2}
\end{aligned}
$$

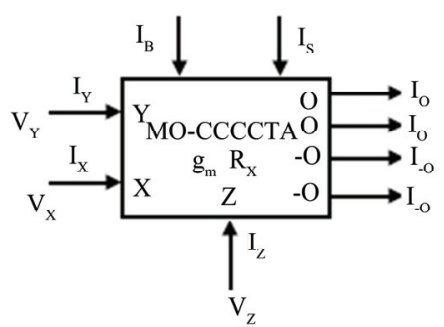

Figure 1. CCCCTA symbol.

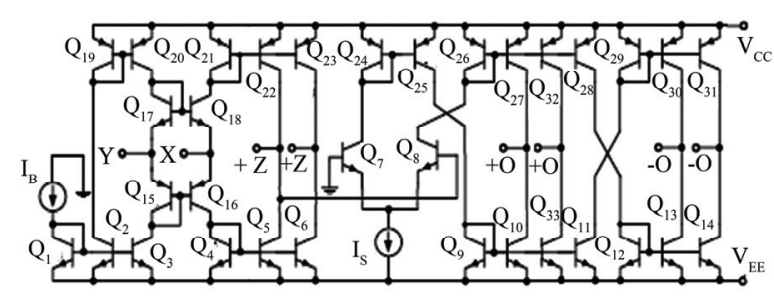

Figure 2. Internal topology of MO-CCCCTA.

It is noted from (7) that simple current matching condition is required to get AP response which is $I_{S 3} I_{B 1}=$ $2 I_{S 1} I_{B 3}$. The pole frequency $\left(\omega_{\mathrm{o}}\right)$, the quality factor $(Q)$ and Bandwidth $(B W) \omega_{\mathrm{o}} / Q$ of each filter response can be expressed as

$$
\begin{gathered}
\omega_{\mathrm{o}}=\left(\frac{g_{m 2}}{C_{1} C_{2} R_{X 2}}\right)^{\frac{1}{2}}, Q=\frac{1}{g_{m 1} R_{X 1}}\left(\frac{C_{1} R_{X 2} g_{m 2}}{C_{2}}\right)^{\frac{1}{2}}, \\
B W=\frac{\omega_{0}}{Q}=\frac{g_{m 1} R_{X 1}}{C_{1} R_{X 2}}
\end{gathered}
$$

Substituting intrinsic resistances as depicted in (2), it yields

$$
\omega_{\mathrm{o}}=\frac{1}{V_{T}}\left(\frac{I_{S 2} I_{B 2}}{C_{1} C_{2}}\right)^{\frac{1}{2}}, Q=\frac{2 I_{B 1}}{I_{S 1}}\left(\frac{I_{S 2} C_{1}}{I_{B 2} C_{2}}\right)^{\frac{1}{2}}
$$

From (9), by maintaining the ratio $I_{B 2}$ and $I_{S 2}$ to be constant, it can be remarked that the pole frequency can be adjusted by $I_{B 2}$ and $I_{S 2}$ without affecting the quality factor. Moreover, the Quality factor can also be adjusted by $I_{B 1}$ or $I_{S 1}$ or both, without affecting the pole frequency. In addition, bandwidth $(B W)$ of the system can be expressed by

$$
B W=\frac{\omega_{0}}{Q}=\frac{1}{V_{T} C_{1}} \frac{I_{S 1} I_{B 2}}{I_{B 1}}
$$

Equations (9) and (10) show that the pole frequency and quality factor of the proposed filter circuit can be tuned independently and electronically with out affecting the bandwidth over the wide range by adjusting the external bias current $I_{S 2}$.

\section{Non-Ideal Analysis}

For non-ideal case, the CCCCTA can be, respectively, 
characterized with the following equations

$$
\begin{gathered}
V_{X i}=\beta_{i} V_{Y i}+I_{X i} R_{X i} \\
I_{Z i}=\alpha_{i} I_{X i} \\
I_{O i}=\gamma_{p i} g_{m i} V_{Z i} \\
I_{-O i}=-\gamma_{n i} g_{m i} V_{Z i}
\end{gathered}
$$

where $\beta_{i}, \alpha_{i}, \gamma_{p i}$, and $\gamma_{n i}$ are transferred ratios of $i^{\text {th }}$ CCCCTA $(I=1,2,3)$ which deviate from 'unity' by the transfer errors. In the case of non-ideal and re-analyzing the proposed filter in Figure 3, it yields the transfer functions as

$$
\begin{aligned}
& T_{L P}(s)=\frac{I_{L P}(s)}{I_{i n}(s)}=-g_{m 1} R_{X 1} \frac{\alpha_{2} \beta_{2} \gamma_{p 1} \gamma_{p 2} g_{m 2}}{s^{2} \alpha_{1} \beta_{1} C_{1} C_{2} R_{X 2}+s \alpha_{2} \beta_{2} \gamma_{p 1} g_{m 1} R_{X 1} C_{2}+\alpha_{1} \beta_{1} \alpha_{2} \beta_{2} \gamma_{n 2} g_{m 2}} \\
& T_{B P}(s)=\frac{I_{B P}(s)}{I_{i n}(s)}=-g_{m 1} R_{X 1} \frac{\frac{\beta_{2} \gamma_{p 1} \gamma_{p 3}}{\left(1+\alpha_{3}\right)} g_{m 3} R_{X 3} C_{2} s}{s^{2} \alpha_{1} \beta_{1} C_{1} C_{2} R_{X 2}+s \alpha_{2} \beta_{2} \gamma_{p 1} g_{m 1} R_{X 1} C_{2}+\alpha_{1} \beta_{1} \alpha_{2} \beta_{2} \gamma_{n 2} g_{m 2}} \\
& T_{H P}(s)=\frac{I_{H P}(s)}{I_{i n}(s)}=g_{m 1} R_{X 1} \frac{s^{2} \gamma_{n 1} C_{1} C_{2} R_{X 2}+\alpha_{2} \beta_{2} g_{m 2}\left(\gamma_{n 1} \gamma_{n 2}-\gamma_{p 1} \gamma_{p 2}\right)}{s^{2} \alpha_{1} \beta_{1} C_{1} C_{2} R_{X 2}+s \alpha_{2} \beta_{2} \gamma_{p 1} g_{m 1} R_{X 1} C_{2}+\alpha_{1} \beta_{1} \alpha_{2} \beta_{2} \gamma_{n 2} g_{m 2}} \\
& T_{B R}(s)=\frac{I_{B R}(s)}{I_{i n}(s)}=g_{m 1} R_{X 1} \frac{\left(s^{2} \gamma_{n 1} C_{1} C_{2} R_{X 2}+\alpha_{2} \beta_{2} \gamma_{n 1} \gamma_{n 2} g_{m 2}\right)}{s^{2} \alpha_{1} \beta_{1} C_{1} C_{2} R_{X 2}+s \alpha_{2} \beta_{2} \gamma_{p 1} g_{m 1} R_{X 1} C_{2}+\alpha_{1} \beta_{1} \alpha_{2} \beta_{2} \gamma_{n 2} g_{m 2}} \\
& T_{A P}(s)=\frac{I_{A P}(s)}{I_{i n}(s)}=-g_{m 1} R_{X 1} \frac{\left(s^{2} \gamma_{p 1} C_{1} C_{2} R_{X 2}-\frac{\beta_{2} \gamma_{p 1} \gamma_{n 3}}{\left(1+\alpha_{3}\right)} g_{m 3} R_{X 3} C_{2} s+\alpha_{2} \beta_{2} \gamma_{p 1} \gamma_{n 2} g_{m 2}\right)}{s^{2} \alpha_{1} \beta_{1} C_{1} C_{2} R_{X 2}+s \alpha_{2} \beta_{2} \gamma_{p 1} g_{m 1} R_{X 1} C_{2}+\alpha_{1} \beta_{1} \alpha_{2} \beta_{2} \gamma_{n 2} g_{m 2}}
\end{aligned}
$$

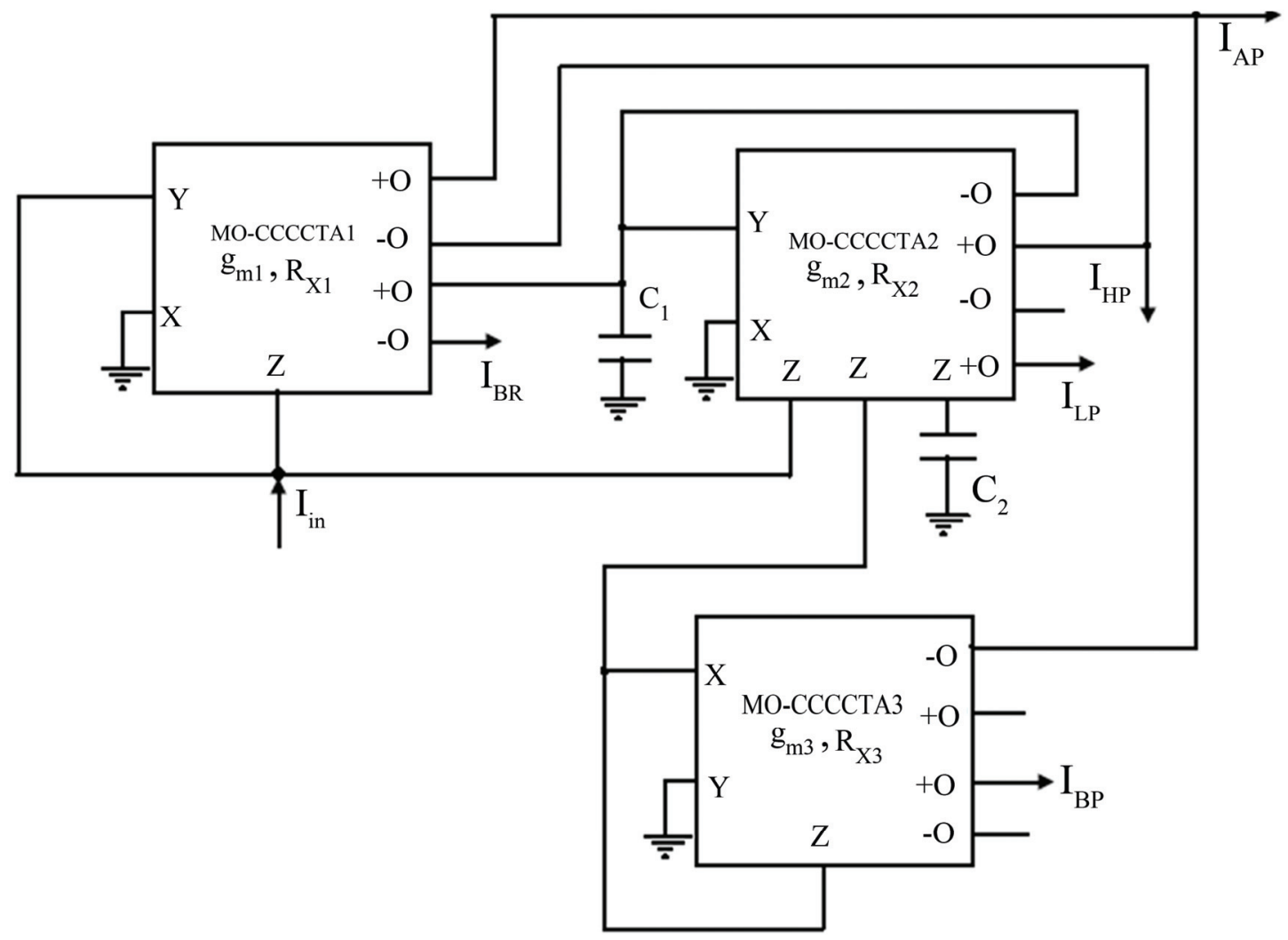

Figure 3. Proposed universal current-controlled current-mode biquad filter employing MO-CCCCTAs and grounded capacitors. 
In this case, the $\omega_{o}$ and $Q$ are changed to

$$
\omega_{\mathrm{o}}=\left(\frac{\alpha_{2} \gamma_{n 2} \beta_{2} g_{m 2}}{C_{1} C_{2} R_{X 2}}\right)^{\frac{1}{2}}, Q=\frac{\alpha_{1} \beta_{1}}{\gamma_{p 1} g_{m 1} R_{X 1}}\left(\frac{\gamma_{n 2} R_{X 2} g_{m 2} C_{1}}{\alpha_{2} \beta_{2} C_{2}}\right)^{\frac{1}{2}}
$$

The active and passive sensitivities of the proposed circuit can be found as

$$
\begin{gathered}
S_{C_{1}, C_{2}, R_{X 2}}^{\omega_{o}}=-\frac{1}{2}, S_{g_{m 2}, \alpha_{2}, \beta_{2}, \gamma_{n 2}}^{\omega_{o}}=\frac{1}{2}, S_{R_{X 1}, g_{m 1}, g_{m 3}, \alpha_{1}, \alpha_{3}, \beta_{1}, \beta_{3}}^{\omega_{o}}=0, \\
S_{R_{X 3}, \gamma_{n 1}, \gamma_{n 3}, \gamma_{p 1}, \gamma_{p 2}, \gamma_{p 3}}^{\omega_{o}}=0 \\
S_{C_{2}, \alpha_{2}, \beta_{2}}^{Q}=-\frac{1}{2}, S_{R_{X 2}, g_{m 2}, C_{1}, \gamma_{n 2}}^{Q}=\frac{1}{2}, S_{\gamma_{p 1}, g_{m 1}, R_{X 1}}^{Q}=-1 \\
S_{\alpha_{1}, \beta_{1}}^{Q}=1 \quad S_{\alpha_{3}, \gamma_{n 1}, \gamma_{n 3}, \gamma_{p 2}, \gamma_{p 3}, \beta_{3}, g_{m 3}}^{Q}=0
\end{gathered}
$$

From the above results, it can be observed that all the sensitivities are low and no longer than one in magnitude.

\section{Simulation Results}

The proposed universal current-mode filter was verified through PSPICE simulations. In simulation, the MOCCCCTA was realized using BJT model as shown in Figure 2, with the transistor model of HFA3096 mixed transistors arrays [12] and was biased with $\pm 1.85 \mathrm{~V} \mathrm{DC}$ power supplies. The SPICE model parameters are given in Table 1. The circuit was designed for $Q=1$ and $f_{o}=$ $\omega_{o} / 2 \pi=3.68 \mathrm{MHz}$. The active and passive components were chosen as $I_{B 1}=I_{B 2}=60 \mu \mathrm{A}, I_{B 3}=30 \mu \mathrm{A} I_{S 1}=I_{S 2}=$ $I_{S 3}=240 \mu \mathrm{A}$ and $C_{1}=C_{2}=0.2 \mathrm{nF}$. Figure 4 shows the simulated gain responses of the $L P, H P, B P, B R$ and $A P$ in current form. Figure 5 shows the phase response of $A P$. The simulation results show the simulated pole frequency as $3.58 \mathrm{MHz}$ that agree quite well with the theoretical analysis.

Figure 6 shows magnitude responses of BP function where $I_{B 2}$ and $I_{S 2}$ are equally set and changed for several values, by keeping its ratio to be constant for constant $Q(=2)$. Other parameters were chosen as $I_{B 1}=240 \mu \mathrm{A}$, $I_{B 3}=30 \mu \mathrm{A}, I_{S 1}=I_{S 3}=240 \mu \mathrm{A}$, and $C_{1}=C_{2}=0.2 \mathrm{nF}$. The pole frequency (in Figure 6) is found to vary as 1.75 $\mathrm{MHz}, 3.43 \mathrm{MHz}$ and $7.52 \mathrm{MHz}$ for three values of $I_{B 2}=$ $I_{S 2}$ as $60 \mu \mathrm{A}, 120 \mu \mathrm{A}$ and $280 \mu \mathrm{A}$, respectively, which shows that pole frequency can be electronically adjusted without affecting the quality factor. Figure 7 shows the magnitude responses of BP function for different values of $I_{S 1}$, by keeping $I_{B 1}=I_{B 2}=60 \mu \mathrm{A}, I_{B 3}=30 \mu \mathrm{A}, I_{S 2}=I_{S 3}=$ $240 \mu \mathrm{A}$, and $C_{1}=C_{2}=0.2 \mathrm{nf}$. The quality factor was found to vary as $7.2,3.81,1.91,0.96,0.49$, by keeping constant pole frequency as $3.35 \mathrm{MHz}$ for five values of $I_{S 1}$ as $30 \mu \mathrm{A}, 60 \mu \mathrm{A}, 120 \mu \mathrm{A}, 240 \mu \mathrm{A}$ and $480 \mu \mathrm{A}$, respectively, which shows that the quality factor of the BP

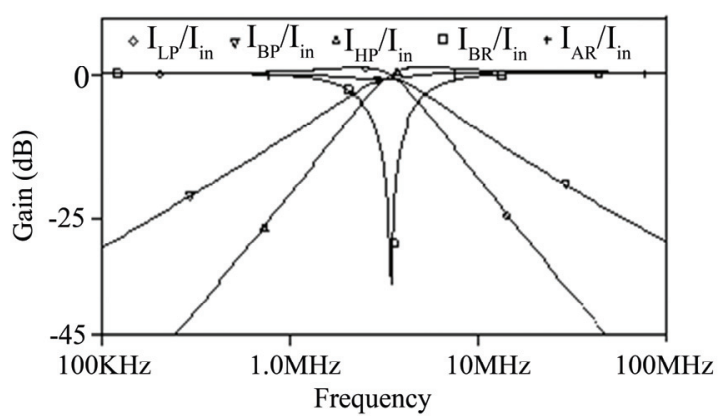

Figure 4. Simulated results of circuit in Figure 3.

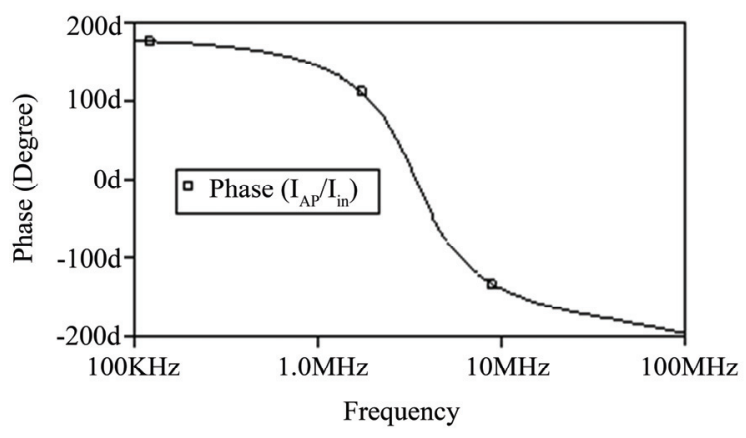

Figure 5. Phase response of AP of circuit in Figure 3.

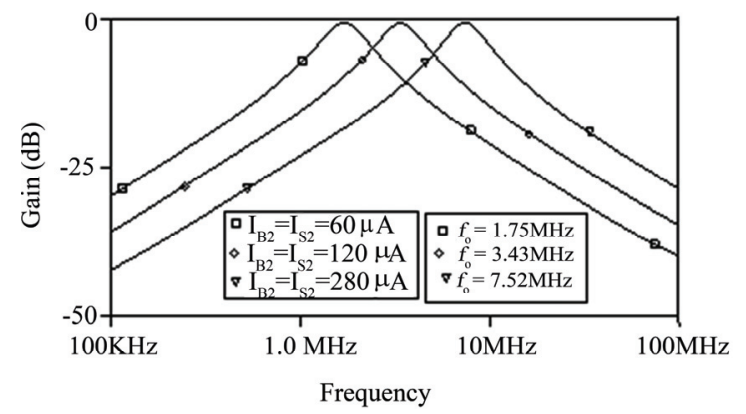

Figure 6. Band Pass responses for different value of $I_{B 2}=I_{S 2}$.

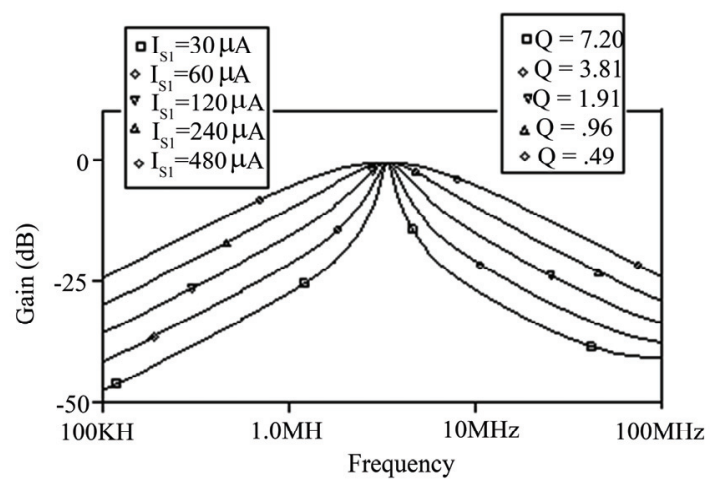

Figure 7. Band Pass responses for different value of $\boldsymbol{I}_{S 1}$.

response can be electronically adjusted without affecting the pole frequency by input bias current $I_{S 1}$. Further simulations were carried out to verify the total harmonic 
Table 1. The SPICE model parameters of HFA3096 mixed transistors arrays.

\begin{tabular}{|c|c|}
\hline .model npn & $\begin{array}{c}\mathrm{Is}=1.80 \mathrm{E}-17, \mathrm{Xti}=3.20, \mathrm{Eg}=1.167, \mathrm{Vaf}=151.0, \mathrm{Bf}=1.10 \mathrm{E}+02, \mathrm{Ne}=2.000, \mathrm{Ise}= \\
1.03 \mathrm{E}-16, \mathrm{IKf}=1.18 \mathrm{E}-02, \mathrm{Xtb}=2.15, \mathrm{Br}=8.56 \mathrm{E}-02, \mathrm{IKr}=1.18 \mathrm{E}-02, \mathrm{Rc}=1.58 \mathrm{E} \\
+02, \mathrm{Cjc}=2.44 \mathrm{E}-14, \mathrm{Mjc}=0.350, \mathrm{Vjc}=0.633, \mathrm{Cje}=5.27 \mathrm{E}-4, \mathrm{Mje}=0.350, \mathrm{Vje}= \\
1.250, \mathrm{Tr}=5.16 \mathrm{E}-08, \mathrm{Tf}=2.01 \mathrm{E}-11, \mathrm{Itf}=2.47 \mathrm{E}-02, \mathrm{Vtf}=6.62, \mathrm{Xtf}=25.98, \mathrm{Rb}= \\
8.11 \mathrm{E}+02, \mathrm{Ne}=2, \mathrm{Isc}=0, \mathrm{Fc}=.5\end{array}$ \\
\hline .model pnp & $\begin{array}{c}\mathrm{Is}=8.40 \mathrm{E}-18, \mathrm{Xti}=3.67, \mathrm{Eg}=1.145, \mathrm{Vaf}=57.0, \mathrm{Bf}=9.55 \mathrm{E}+01, \mathrm{Ne}=2.206, \mathrm{Ise}= \\
3.95 \mathrm{E}-16, \mathrm{IKf}=2.21 \mathrm{E}-03, \mathrm{Xtb}=1.82, \mathrm{Br}=3.40 \mathrm{E}-01, \mathrm{IKr}=2.21 \mathrm{E}-03, \mathrm{Rc}=1.43 \mathrm{E} \\
+02, \mathrm{Cjc}=3.68 \mathrm{E}-14, \mathrm{Mjc}=0.333, \mathrm{Vjc}=0.700, \mathrm{Cje}=4.20 \mathrm{E}-14, \mathrm{Mje}=0.560, \mathrm{Vje} \\
=.8950, \mathrm{Tr}=2.10 \mathrm{E}-08, \mathrm{Tf}=6.98 \mathrm{E}-11, \mathrm{Itf}=2.25 \mathrm{E}-02, \mathrm{Vtf}=1.34, \mathrm{Xtf}=12.31, \mathrm{Rb} \\
=5.06 \mathrm{E}+02, \mathrm{Ne}=2, \mathrm{Isc}=0, \mathrm{Fc}=.5\end{array}$ \\
\hline
\end{tabular}

distortion (THD). The circuit was verified by applying a sinusoidal input current of varying frequency and amplitude of $60 \mu \mathrm{A}$. The THD measured at the LP output are found to be less than $3 \%$ while frequency is varied from $30 \mathrm{KHz}$ to $1 \mathrm{MHz}$. Moreover, the circuit was also simulated for THD analysis at LP output, by applying sinusoidal input current of varying amplitude and constant frequency. Figure 8 shows the variation of THD versus applied sinusoidal input current at frequency of $500 \mathrm{KHz}$ for the proposed filter. It can be seen that the THD of the proposed filter circuit for the input current signal less than $100 \mu \mathrm{A}$, remain in moderate range, i.e., $3 \%$. The time domain response of current-mode $L P$ output $\left(I_{L P}\right)$ is shown in Figure 9. It was observed that $120 \mu \mathrm{A}$ peak to peak input current sinusoidal signal levels having frequency $500 \mathrm{KHz}$ are possible without significant distortions. Thus both THD analysis and time domain response of LP output confirm the practical utility of the proposed current-mode filter circuit.

\section{Conclusions}

A new universal current-controlled current-mode biquad filter employing three MO-CCCCTAs and two grounded capacitors is proposed. The proposed filter offers the following advantages: 1) employment of only three active elements; 2) ability of realizing all current-mode standard filter

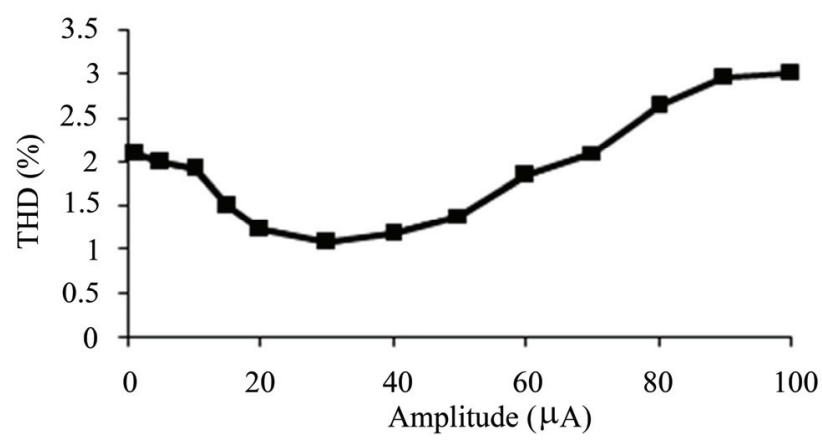

Figure 8. Variation of THD of LP output with input current signal at $500 \mathrm{KHz}$.

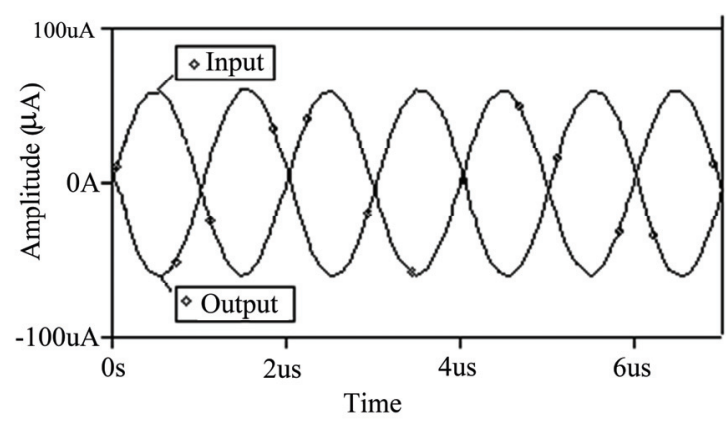

Figure 9. The time domain input waveform and corresponding response at LP output.

functions simultaneously; 3) employment of Both grounded capacitors; 4) low sensitivity figures and low THD; 5) electronically orthogonal tunability of $\omega_{0}$ and $\left.Q ; 6\right)$ availability of explicit current outputs (i.e., high impedance output nodes) without requiring any additional active elements; 7) suitable for high frequency applications - all of which are not available simultaneously in any of the previously reported current-controlled current-mode biquad filter of $[6,8,10,12-19,21-23]$. With above mentioned features it is very suitable to realize the proposed circuit in monolithic chip to use in battery powered, portable electronic equipments such as wireless communication system devices.

\section{References}

[1] A. S. Sedra and K. C. Smith, "Microelectronics Circuits," Rinehart and Winston, Holt, 2003.

[2] C. Toumazou, F. J. Lidgey and D. G. Haigh, "Analogue IC Design: The Current-Mode Approach," London Peter Peregrinus, London, 1990.

[3] M. Siripruchyanun and W. Jaikla, "Current Controlled Current Conveyor Transconductance Amplifier (CCCCTA): A Building Block for Analog Signal Processing," Electrical Engineering, Vol. 90, No. 6, 2008, pp. 443-453.

[4] S. V. Singh, S. Maheshwari, J. Mohan and D. S. Chauhan, "An Electronically Tunable SIMO Biquad Filter Using CCCCTA," Contemporary Computing, CCIS, Vol. 40, 
2009, pp. 544-555.

[5] A. M. Soliman, "New Current-Mode Filters Using Current Conveyors," International Journal of Electronics and Communications (AEÜ), Vol. 51, No. 3, 1997, pp. 275278.

[6] S. Minaei and S. Türköz, "New Current-Mode CurrentControlled Universal Filter with Single Input and Three Outputs," International Journal of Electronics, Vol. 88, No. 3, 2001, pp. 333-337.

[7] R. Senani, "New Current Mode Biquad Filter," International Journal of Electronics, Vol. 73, No. 4, 1992, pp. 735-742.

[8] A. U. Keskin, D. Biolek, E. Hancioglu and V. Biolkova, "Current-Mode KHN Filter Employing Current Differencing Transconductance Amplifiers," International Journal of Electronics and Communications (AEÜ), Vol. 60, No. 6, 2006, pp. 443-446.

[9] M. Soliman, "Current Mode Universal Filters with Grounded Passive Elements and Using Single Output Current Conveyors," Journal of Active and Passive Electronics Devices, Vol. 4, 2009, pp. 55-62.

[10] S. Maheshwari and I. A. Khan, "Novel Cascadable Current-Mode Translinear-C Universal Filter," Active Passive Electronics Components, Vol. 27, No. 4, 2004, pp. 215-218.

[11] C. Wang, Y. Zhao, Q. Zhang and S. Du, "A New Current Mode SIMO-Type Universal Biquad Employing MultiOutput Current Conveyors (MOCCIIs)," Radioengineering, Vol. 18, No. 1, 2009, pp. 83-88.

[12] R. Senani, V. K. Singh, A. K. Singh and D. R. Bhaskar, "Novel Electronically Controllable Current-Mode Universal Biquad Filter," The Institute of Electronics, Information and Communication Engineers, Vol. 1, No. 14, 2004, pp. 410-415.

[13] W. Kiranon, J. Kesorn and N. Kamprasert, "Electronically Tunable Multi-Function Translinear-C Filter and Oscillators," Electronics Letters, Vol. 33, No. 7, 1997, pp. 573-574.

[14] S. Maheshwari and I. A. Khan, "High Performance Ver- satile Translinear-C Universal Filter," Journal of Active and Passive Electronics Devices, Vol. 1, No. 2, 2005, pp. 41-51.

[15] M. T. Abuelma'atti and N. A. Tassaduq, "New CurrentMode Current Controlled Filters Using Current-Controlled Conveyor," International Journal of Electronics, Vol. 85, No. 4, 1998, pp. 483-488.

[16] T. Katoh, T. Tsukutani, Y. Sumi and Y. Fukui, "Electronically Tunable Current-Mode Universal Filter Employing CCCIIs and Grounded Capacitors," International Symposium on Intelligent Signal Processing and Communications Systems, 2006, pp. 107-110.

[17] C. Wang, H. Liu and Y. Zhao, "A New Current-Mode Current-Controlled Universal Filter Based on CCCII ( \pm )," Circuits System Signal Processing, Vol. 27, No. 5, 2008, pp. 673-682.

[18] S. Minaei and S. Türköz, "Current-Mode Electronically Tunable Universal Filter Using Only Plus-Type Current Controlled Conveyors and Grounded Capacitors," Electronics and Telecommunications Research Institute Journal, Vol. 26, No. 4, 2004, pp. 292-296.

[19] M. T. Abuelma'atti and N. A. Tassaduq, "A Novel Single-Input Multiple-Output Current-Controlled Universal Filter," Microelectronics Journal, Vol. 29, No. 11, 1998, pp. 901-905.

[20] S. Maheshwari, "Current-Mode Filters with High Output Impedance and Employing only Grounded Components," WSEAS Transactions on Electronics, Vol. 5, No. 1, 2008, pp. 238-243.

[21] W. Jaikla and M. Siripruchyanun, "A Cascadable Current-Mode Universal Biquadratic Filter Using MOCCCCTAs," IEEE Conference, Pisa, 2008, pp. 952-955.

[22] D. Biolek and V. Biolkova, "CDTA-C Current-Mode Universal $2^{\text {nd }}$ Order Filter," Proceeding of the 5th International Conference on Applied Informatics and Communications, Malta, 2003, pp. 411-414.

[23] W. Tangsrirat and W. Surakampontorn, "Systematic of Cascadable Current-Mode Filters Using CDTAs," Frequenz, Vol. 60, No. 11-12, 2006, pp. 241-245. 